\title{
Análise da regulamentação das cooperativas de trabalho pela lei $n^{0} \mathbf{1 2 . 6 9 0 / 2 0 1 2}$
}

\author{
Regulatory review of worker cooperatives \\ by Law No. 12.690/2012
}

\author{
Eloísa Dias Gonçalves \\ Mestranda em Direito (UFPR) \\ dg.eloisa@gmail.com
}

\begin{abstract}
Resumo: Na esteira das transformações que marcaram o mundo do trabalho a partir da reestruturação produtiva ocorrida no final do século XX, as cooperativas de trabalho se constituíram no Brasil como uma forma de organização dos trabalhadores. Todavia, houve também a proliferação de cooperativas fraudulentas, como forma de precarização das relações de trabalho e desoneração do capital. A criação de um marco jurídico próprio para regulamentação das cooperativas de trabalho foi proposta como solução para as fraudes e a garantia de direitos sociais aos trabalhadores cooperados. Todavia, a análise da Lei Federal $n^{0}$ 12.690/2012 denota alguns limites dessa proposta, bem como os impactos para os empreendimentos solidários autênticos. Nesse sentido, inclusive, analisa-se a posição do Movimento Nacional de Catadores de Materiais Recicláveis sobre a referida lei.
\end{abstract}

Palavras-chave: cooperativas de trabalho, precarização, catadores de materiais recicláveis, reestruturação produtiva, Movimento Nacional de Catadores de Materiais Recicláveis.

Abstract: In the wake of the transformations that have marked the Labor world from the productive restructuring in the late 20th century, work cooperatives were formed in Brazil as a way of to organize workers. However, there was also a propagation of fraudulent cooperatives as a form of casualization of the labor relations and to unburden capital. The creation of a legal boundary exclusively for the regulation of labor unions has been proposed as a solution to frauds and to ensure the social rights to the cooperative workers. However, analysis of the Federal Law No. 12.690/2012 denotes some limits of this proposal, as well as the impacts to the authentics solidarity enterprises. In this sense, we analyze the position of the National Movement of Recyclable Materials Collectors on the mentioned Law.

Keywords: work cooperatives, job insecurity, recyclable waste collectors, productive restructuring, national movement of recyclable materials collectors.

Originais recebidos em: 23/03/2014

Aceito para publicação em: 27/06/2014

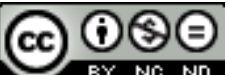

Comercial-Vedada a criação de obras derivadas 3.0 Unported License. 


\section{Introdução}

O mundo do trabalho vem sofrendo significativas alterações desde as últimas décadas do século XX, sendo que nesse período o Brasil foi marcado pelo processo de reestruturação produtiva, amparado no ideário neoliberal, em que o desemprego estrutural, as privatizações, a flexibilização e a precariedade das relações de trabalho ganharam destaque.

Ricardo Antunes aponta como característicos da fase contemporânea do capitalismo a desproletarização do trabalho industrial, paralela a uma expansão do trabalho assalariado no setor de serviços, além de uma heterogeneização do trabalho e uma subproletarização intensificada. "O mais brutal resultado dessas transformações é a expansão, sem precedentes na era moderna, do desemprego estrutural, que atinge o mundo em escala global." (ANTUNES, 2010, p. 47).

Todavia, não há que se falar em "fim do trabalho", mas em uma nova morfologia, que permite a coexistência de diversas modalidades de trabalho, mais desregulamentadas e distantes da legislação trabalhista. "Em outras palavras, em plena era da informatização do trabalho, do mundo maquinal e digital, estamos conhecendo a época da informalização do trabalho, dos terceirizados, precarizados, subcontratados, flexibilizados, trabalhadores em tempo parcial” (ANTUNES, 2010, p. 106).

Assim, uma das principais consequências do processo de reestruturação produtiva e da nova divisão internacional do trabalho é a precarização estrutural do trabalho. Helena Hirata aponta três indicadores do trabalho precário: a ausência de proteção social e de direitos sociais, relacionados principalmente com a informalidade; a expansão do trabalho em tempo parcial, normalmente de baixa remuneração; e a relação entre os baixos níveis de qualificação e a remuneração baixa, sendo que mesmo empregos formais podem ser precários devido ao salário baixo (HIRATA, 2009, p. 26).

Nesse contexto, em que o mito do pleno emprego perde força e os trabalhadores não encontram mais no emprego formal e regulamentado a sua subsistência, parecem inevitáveis a sua submissão a condições de trabalho precárias e a busca por alternativas ao emprego formal, sendo que as cooperativas são retomadas como uma dessas opções.

\section{A reestruturação produtiva e a expansão das cooperativas de trabalho}


O processo de reestruturação produtiva acarretou diversos impactos no mundo do trabalho, gerando uma série de respostas pelos governos, empresas, trabalhadores e organizações sociais e sindicais. Em decorrência do alastramento do desemprego e da situação de penúria, a que muitas famílias foram submetidas, diversas cooperativas foram formadas no Brasil por iniciativa popular e com apoio de organizações sociais (igrejas, sindicatos, movimentos sociais, ONGs e universidades), pautadas, sobretudo, na busca por uma alternativa de renda, já que estavam excluídos do mercado formal de trabalho.

Assim, sobretudo a partir dos anos 1990, os trabalhadores que sofreram mais diretamente as transformações no mundo do trabalho são incentivados a constituírem cooperativas para, por meio delas, garantirem sua sobrevivência. Aliado a isso, desenvolve-se todo um debate em torno da economia solidária, propondo as práticas autogestionadas como forma não apenas de enfrentamento da crise e geração de renda, mas como o desenvolvimento de um projeto social de enfrentamento ao capitalismo e construção de outra economia e sociedade. Nesse sentido, essas experiências procuram retomar os princípios originais do cooperativismo, calcado na democracia, na autogestão, na igualdade. "Portanto, o contexto de expansão das cooperativas de trabalho no Brasil está diretamente relacionado com o aumento das formas de contratação flexíveis e com o crescimento do desemprego estrutural.” (SILVA, 2007, p. $150)$.

Todavia, paralelo a isso, observa-se outro fenômeno: a constituição de cooperativas fraudulentas (as chamadas cooperfraudes) que, ao invés de serem uma organização autônoma dos cooperados, são criadas por empresas para intermediação de mão-de-obra. Assim, estas deixam de arcar com os custos dos direitos trabalhistas, enquanto seus antigos empregados, agora "cooperados", são submetidos a condições de trabalho precarizadas.

Nos anos 1990, assistimos, no Brasil, a uma larga utilização da terceirização
via cooperativas de trabalho e de produção no setor industrial. Este fato deve
ser compreendido como uma das expressões do processo de reorganização
industrial com vistas a adequar este setor ao novo padrão de competição
mundial resultante do movimento de reestruturação produtiva. (SILVA,
2007, p. 147).

Assim, há uma verdadeira apropriação da forma cooperativa para atender aos interesses do capital. “As 'cooperativas' patronais têm sentido contrário ao projeto original das cooperativas de trabalhadores, pois são verdadeiros empreendimentos para 
destruir direitos e aumentar ainda mais as condições de precarização da classe trabalhadora." (ANTUNES, 2010, p. 108).

Portanto, as cooperativas passaram a ser utilizadas como resposta à reestruturação produtiva: por vezes eram a resposta dos trabalhadores marginalizados, em busca da geração de renda; já em outros casos, eram a saída apresentada pelos empresários para a diminuição de custo e a burla aos direitos trabalhistas.

Esta é uma das origens do surto de cooperativas de trabalho. Empresas criam cooperativas de trabalho, com seus estatutos e demais apanágios legais, as registram devidamente e depois mandam seus empregados se tornarem membros delas, sob pena de ficar sem trabalho. Os empregados são demitidos, muitas vezes de forma regular, e continuam a trabalhar como antes, ganhando o mesmo salário direto, mas sem o usufruto dos demais direitos trabalhistas. Estas são as falsas cooperativas também conhecidas como cooperfraudes e outros epítetos. São cooperativas apenas no nome, arapucas especialmente criadas para espoliar os trabalhadores forçados a se inscrever nelas. (SINGER, 2004).

Desde logo, importante destacar que esses dois fenômenos foram potencializados com a inclusão do parágrafo único do art. 442 da Consolidação das Leis do Trabalho, em 1994, que dispõe: "Qualquer que seja o ramo de atividade da sociedade cooperativa, não existe vínculo empregatício entre ela e seus associados, nem entre estes e os tomadores de serviços daquela". A inovação ao ordenamento jurídico está na previsão expressa de inexistência de vínculo empregatício entre os cooperados e os tomadores de serviço da cooperativa.

Independente da razão que motivou a inclusão desse dispositivo, o fato é que ele institucionaliza a possibilidade de terceirização via cooperativa, dando segurança jurídica às empresas tomadoras de serviço, que nele se alicerçam para se esquivar da responsabilização trabalhista. Ainda que essa presunção de inexistência de relação de emprego seja relativa, é evidente que ela contribuiu para a disseminação das cooperfraudes, pois parte-se do pressuposto de que não há que se falar em responsabilidade das empresas perante os cooperados.

Diante disso, o Ministério do Trabalho editou, em 28 de setembro de 1995, a Portaria $n^{\circ} 925$, que dispõe sobre a fiscalização do trabalho na empresa tomadora de serviço de sociedade cooperativa. Em seu artigo $1^{\circ}$ aduz que:

O Agente da Inspeção do Trabalho, quando da fiscalização na empresa tomadora de serviços de sociedade cooperativa, no meio urbano ou rural, procederá ao levantamento físico, objetivando detectar a existência dos requisitos da relação de emprego entre a empresa tomadora e os cooperados, nos termos do art. $3^{\circ}$ da CLT. (MTE, 1995). 
Assim, percebe-se que em decorrência da proliferação de cooperativas fraudulentas a partir da edição do parágrafo único do art. 442 da CLT foi necessário se estabelecer regras para fiscalização das empresas tomadoras de serviço de cooperativas. Com isso, averígua-se se a terceirização estava ocorrendo dentro dos parâmetros legais ou se a constituição da cooperativa não passava de um subterfúgio para fraudar a legislação trabalhista, o que resultou em uma série de medidas judiciais.

\begin{abstract}
A fiscalização e o ministério público, na verdade tentam distinguir entre cooperativas de trabalho e cooperativas que chamam de mão-de-obra. As cooperativas de trabalho seriam as que vendem o produto do trabalho dos membros, desde que seja feito com meios próprios de produção e em recinto da cooperativa. As cooperativas de 'mão-de-obra' seriam as que vendem o produto do trabalho (serviço) feito com meios de produção e no local do comprador. (SINGER, 2004).
\end{abstract}

Todo esse processo colocou em discussão maneiras de se resolver o seguinte impasse: como permitir a expansão das cooperativas como forma de geração de renda para os trabalhadores, sem que elas se tornem mero instrumento proposto pelo capital para garantir a terceirização e a precarização do trabalho?

\title{
A regulamentação das cooperativas de trabalho
}

Conforme já apontado, paralelo ao processo de reestruturação produtiva vimos se desenvolver o projeto da economia solidária, que recebeu o apoio do poder público em alguns municípios e estados, dando origem a uma série de políticas públicas voltadas ao fomento e à consolidação dos empreendimentos solidários, seja no formato de associação ou de cooperativas.

Contudo, é em 2003, com o início do governo Lula e por pressão dos movimentos e organizações ligados à economia solidária, que essa política é alçada a nível nacional, criando-se a SENAES - Secretaria Nacional de Economia Solidária, que integra o Ministério do Trabalho e Emprego. "A ação da secretaria objetiva apoiar e induzir o crescimento das iniciativas, mas tendo como diretrizes as experiências e propostas já vinculadas pelos grupos envolvidos - ONGs, sindicatos, igrejas e unidades econômicas cooperativadas.” (BARBOSA, 2007, p. 229).

No Brasil, a questão da recepção do Estado à economia solidária pode ser referida a dois campos de ação: as iniciativas do Poder Público, como agente fomentador da constituição de empreendimentos solidários, através da implementação de políticas públicas que estimulem a sua criação e desenvolvimento e a ação reguladora do Estado, voltada à promoção de mudanças institucionais, de modo a permitir a assimilação desses 'novos 
empreendimentos', em suas diversas formas de manifestação, no seu ordenamento jurídico. (PEREIRA, 2008, p. 80).

A partir dos documentos oficiais elaborados pela SENAES, Rosangela Barbosa aponta como seus principais objetivos específicos: a articulação de políticas de finanças solidárias; a revisão da legislação sobre cooperativas e a propositura do estatuto do empreendimento autogestionário; o fortalecimento dos empreendimentos por meio de fomento material, articulação das cadeias produtivas e apoio ao comércio justo e ao consumo ético; o estímulo à produção de conhecimentos e sistemas de avaliação e informações sobre economia solidária; e o fortalecimento dos espaços de organização da sociedade civil e entes governamentais para formulação de políticas públicas para o setor (2007, p. 231).

A criação da SENAES representou a incorporação à política governamental da maior parte das pautas reivindicadas desde a década de 1990 pelos movimentos sociais e organizações empenhados na construção da economia solidária. Ainda que muito celebrado, esse processo tem sido questionado, sobretudo por conta dos limites que apresenta para os movimentos sociais, bem como pela burocratização e dependência dele decorrentes.

Assim, a discussão em torno da economia solidária e, mais especificamente, das cooperativas de trabalho, passou a ser feita, dentro do governo federal, no âmbito da SENAES. Sobre essa temática, importante destacar a posição de Paul Singer, nomeado como secretário nacional da economia solidária:

Em suma, em vez de perseguir algumas formas de precarização do trabalho, como as cooperativas ditas de 'mão-de-obra', na vã esperança de restaurar o assalariamento regular, o que precisamos fazer é generalizar os direitos trabalhistas como direitos humanos de todos que trabalham, sejam autônomos individuais ou coletivos, sejam assalariados ou estatutários. (SINGER, 2004).

É justamente nesse sentido que se consolidou a proposta apresentada pela SENAES para enfrentar as inúmeras experiências fraudulentas que têm se acobertado sob o manto da economia solidária: a regulamentação das cooperativas de trabalho, com a extensão dos direitos sociais do trabalho aos cooperados.

Cumpre esclarecer que a Lei Federal $n^{\circ}$ 5.764/1971 - que ainda hoje é responsável por estabelecer o regime jurídico das cooperativas, mesmo que tenha sofrido algumas modificações a partir da Constituição Federal e do Código Civil de 2002 - não estabelece uma regulamentação específica para as cooperativas de trabalho. Estas, em verdade, foram se consolidando como prática social, o que impôs a necessidade de sua definição para adequação aos parâmetros gerais do cooperativismo. 
Assim, desde o seu início a SENAES tem procurado formas de combater os empreendimentos que se valem da estrutura do trabalho cooperado para burlar a legislação trabalhista. A partir de um grupo de trabalho focado na questão do marco jurídico, a SENAES propôs tanto uma nova legislação para o cooperativismo, como uma regulamentação específica das cooperativas de trabalho. Essa última foi aprovada no final de 2012 (Lei Federal n. 12.690/2012), o que demonstra a atualidade desse debate e a importância de se compreender as concepções de economia solidária e de trabalho defendidas pela Secretaria.

Desde a sua criação, a SENAES desenvolve (e se envolve) em iniciativas de elaboração e debate do marco legal da ES a partir de vários fóruns constituídos por iniciativa do Governo Federal. Destaca-se a atuação da SENAES nas questões voltadas ao marco jurídico do cooperativismo, com proposição de legislação específica para as Cooperativas de Trabalho, do cooperativismo social e da Lei Geral do Cooperativismo. (SENAES/MTE, 2012, p. 46)

A Lei $n^{\circ}$ 12.690/2012 define as cooperativas de trabalho como "a sociedade constituída por trabalhadores para o exercício de suas atividades laborativas ou profissionais com proveito comum, autonomia e autogestão para obterem melhor qualificação, renda, situação socioeconômica e condições gerais de trabalho" (BRASIL, 2012).

O mecanismo legal apresentado como forma de combate às cooperfraudes fundamenta-se no raciocínio de que, se as cooperativas também tiverem que arcar com os custos dos direitos sociais do trabalho, não será "vantajoso" utilizá-las para redução dos encargos. Com isso, em tese, evita-se a criação de cooperativas para precarização do trabalho, já que estariam garantidos aos trabalhadores os direitos trabalhistas, mesmo quando cooperados e não ligados diretamente às empresas.

A generalização dos direitos acabaria de uma vez com a necessidade prática
de distinguir cooperativa de verdade ou de mentira. As falsas cooperativas
têm como única finalidade deixar de pagar o ônus destes direitos; se a
fiscalização trabalhista pudesse obrigá-las a cumprir a legislação, cessaria sua
razão de ser. As cooperativas de trabalho autênticas perderiam a
possibilidade de se auto-explorar para obter contratos, como muitas vezes
fazem. Teriam que disputar em condições de igualdade os mercados com
empresas capitalistas, outras cooperativas e outros tipos de sociedade.
(SINGER, 2004).

Em 2004 foi proposto projeto de lei que, após oito anos de tramitação, foi aprovado, resultando na Lei Federal $n^{\circ} 12.690 / 2012$, que dispõe sobre a organização e o funcionamento das Cooperativas de Trabalho; institui o Programa Nacional de Fomento às Cooperativas de Trabalho - PRONACOOP. 
Logo, cumpre realizar uma análise da referida lei, para apontar em que medida ela contribui para o combate às cooperfraudes e, também, qual seu impacto para as cooperativas autênticas, criadas pelos trabalhadores em resposta ao processo de reestruturação produtiva vivenciado no país. Além disso, procurará se apontar qual a contribuição oferecida pela regulamentação das cooperativas de trabalho, considerando a precarização estrutural do trabalho.

\section{Análise da Lei Federal nº 12.690/2012}

De acordo com Paul Singer, a principal forma para se garantir que as cooperativas de trabalho não sejam utilizadas como subterfúgio para a precarização do trabalho é atribuir aos seus cooperados os mesmos direitos que outros trabalhadores possuem.

Na esteira dessa concepção, a Lei Federal no 12.690 prevê, em seu art. $7^{\circ}$, que as cooperativas de trabalho devem garantir aos seus sócios um rol mínimo de direitos, qual seja: retiradas não inferiores ao piso da categoria profissional e, na ausência deste, não inferiores ao salário mínimo; duração do trabalho normal não superior a 8 horas diárias e 44 horas semanais; repouso semanal e anual remunerados; retirada para o trabalho noturno superior à do diurno; adicional sobre a retirada para as atividades insalubres ou perigosas; seguro de acidente de trabalho. Além disso, possibilita a previsão estatutária de outros direitos sociais a serem garantidos aos cooperados.

$\mathrm{O}$ art. 17 da lei estabelece a competência do Ministério do Trabalho e Emprego para fiscalizar o seu cumprimento, prevendo a responsabilização dos cooperados e da própria cooperativa em caso de desrespeito. Como bem pontua Selma Cristina Silva: "há um processo de transferência para os trabalhadores (agora na condição de cooperados) dos custos e direitos trabalhistas e sociais. Em outros termos, com esse processo as empresas contratantes se desoneram parcialmente dos custos do trabalho." (SILVA, 2007, p. 151).

Ora, o mecanismo previsto legalmente para coibir a constituição das cooperativas fraudulentas, além de assegurar melhores condições de trabalho aos trabalhadores cooperados, mostra-se falho, como se passa a demonstrar. A lei prevê que as cooperativas devem garantir direitos sociais aos cooperados. Com isso, objetiva tornar "pouco atraente" a utilização das cooperativas como forma de terceirização de 
mão-de-obra, já que elas também teriam que arcar com os custos financeiros desses direitos. Todavia, a própria lei mantém desonerado o contratante da cooperativa.

Assim, continua sendo possível constituir uma cooperativa para prestar determinado serviço ou oferecer um produto por um preço inferior ao do mercado, seja porque a lei não garantiu aos cooperados os mesmos direitos previstos na CLT para os empregados, seja porque a única responsabilidade do contratante está relacionada ao respeito às normas de saúde e segurança. Logo, caso a cooperativa não consiga garantir aos seus cooperados os direitos sociais previstos no art. $7^{\circ}$ da Lei $\mathrm{n}^{\circ} 12.690$, o tomador do serviço não será responsabilizado, mas, sim, a própria cooperativa.

Essa solução apresentada pela SENAES já havia sido criticada pelo Fórum Brasileiro de Economia Solidária (FBES) quando o projeto de lei encontrava-se em tramitação. O FBES já alertava para o fato de que a previsão legal de uma série de direitos sociais aos cooperados, sob responsabilidade da cooperativa, poderia servir, em verdade, para inviabilizar os empreendimentos solidários organizados pelos próprios trabalhadores, ao invés de coibir as cooperfraudes. Nesse sentido, inclusive, é que fizeram uma proposta de regulamentação das cooperativas de trabalho diferenciada:

Já o anteprojeto do FBES (Anexo II), em seu Art. $7^{\circ}$, conclama as cooperativas de trabalho a buscarem alcançar benefícios para os seus cooperados, "em níveis equivalentes ou superiores aos da legislação trabalhista em vigor" e dispõe sobre a constituição de fundos para garantir tais benefícios, porém "de acordo com suas condições financeiras e econômicas". Em outras palavras, para o Fórum é desejável que a cooperativa estenda aos seus cooperados os direitos do trabalhador assalariado, mas tal garantia dependerá de sua capacidade financeira. (PEREIRA, 208, p. 109)

A Lei $n^{\circ} 12.690 / 2012$ prevê, em seu art. $4^{\circ}$, duas modalidades de cooperativas de trabalho: as de produção e as de serviço. Aquelas são constituídas por sócios que contribuem com trabalho para a produção em comum de bens, sendo que a cooperativa é quem detém os meios de produção. Já essas são constituídas para a prestação de serviços especializados a terceiros, sem a presença dos pressupostos da relação de emprego. Assim, o que diferencia esses tipos de cooperativa é o produto final por elas oferecido: um bem ou a prestação de um serviço.

Conforme já exposto, uma das principais razões para a regulamentação das cooperativas do trabalho é o combate às cooperativas fraudulentas, sendo que a maior parte delas era usada como forma de intermediação de mão-de-obra subordinada. Essa preocupação está estampada no art. $5^{\circ}$ da Lei $n^{\circ}$ 12.690, que diz: “A Cooperativa de Trabalho não pode ser utilizada para intermediação de mão de obra subordinada.”. 
Mas a partir da tipologia prevista na própria lei é possível perceber que são as cooperativas de trabalho de serviço (art. $4^{\circ}$, II) aquelas que oferecem maior potencial para fraudar a legislação trabalhista. Para coibir essa prática, foram previstos algumas obrigações e sanções específicas para essas cooperativas, como a necessidade de uma coordenação específica para os serviços prestados fora do estabelecimento da cooperativa, sob pena de caracterização de intermediação de mão-de-obra, bem como a responsabilidade solidária do contratante da cooperativa pelo cumprimento das normas de saúde e de segurança do trabalho ${ }^{1}$.

Ainda no que se refere à intermediação de mão-de-obra, a referida lei prevê uma série de sanções à própria cooperativa e aos seus responsáveis. Veja-se:

Art. 17. Cabe ao Ministério do Trabalho e Emprego, no âmbito de sua competência, a fiscalização do cumprimento do disposto nesta Lei.

$\S 1^{\circ}$ A Cooperativa de Trabalho que intermediar mão de obra subordinada e os contratantes de seus serviços estarão sujeitos à multa de R\$ 500,00 (quinhentos reais) por trabalhador prejudicado, dobrada na reincidência, a ser revertida em favor do Fundo de Amparo ao Trabalhador - FAT. [...]

Art. 18. A constituição ou utilização de Cooperativa de Trabalho para fraudar deliberadamente a legislação trabalhista, previdenciária e o disposto nesta Lei acarretará aos responsáveis as sanções penais, cíveis e administrativas cabíveis, sem prejuízo da ação judicial visando à dissolução da Cooperativa.

Dessa forma, percebe-se que as principais sanções são direcionadas aos cooperados e à própria cooperativa, ao invés de serem imputadas àqueles que se beneficiam da gestão fraudulenta das cooperativas. Assim, é o próprio trabalhador, que se encontra em uma relação de trabalho precarizada, pois submetido à terceirização via cooperativa, que deverá suportar as sanções legais, o que de forma alguma contribui com o objetivo maior de se combater as cooperativas fraudulentas.

Ora, além de garantir aos cooperados menos direitos do que aqueles que os trabalhadores assalariados possuem, a Lei no 12.690 imputa - em última análise - aos próprios cooperados a responsabilidade pela garantia desses direitos, mantendo desonerada a empresa que contrata a cooperativa.

\footnotetext{
${ }^{1}$ Art. $7^{\mathbf{0}}$. $\mathbf{6}^{\mathbf{0}}$ As atividades identificadas com o objeto social da Cooperativa de Trabalho prevista no inciso II do caput do art. 4o desta Lei, quando prestadas fora do estabelecimento da cooperativa, deverão ser submetidas a uma coordenação com mandato nunca superior a 1 (um) ano ou ao prazo estipulado para a realização dessas atividades, eleita em reunião específica pelos sócios que se disponham a realizá-las, em que serão expostos os requisitos para sua consecução, os valores contratados e a retribuição pecuniária de cada sócio partícipe.

Art. 9' O contratante da Cooperativa de Trabalho prevista no inciso II do caput do art. 4o desta Lei responde solidariamente pelo cumprimento das normas de saúde e segurança do trabalho quando os serviços forem prestados no seu estabelecimento ou em local por ele determinado.

Art. 17, $\S 2^{\mathbf{0}}$ Presumir-se-á intermediação de mão de obra subordinada a relação contratual estabelecida entre a empresa contratante e as Cooperativas de Trabalho que não cumprirem o disposto no $\S 60$ do art. 7 o desta Lei.
}

Em Debat: Rev. Dig., ISSNe 1980-3532, Florianópolis, n. 10, p. 88-104, jul-dez, 2013. 
Por outro lado, para que os trabalhadores mantenham a cooperativa regular e não sejam penalizados, têm que garantir esses direitos a eles próprios. Esse mecanismo, evidentemente, ignora a realidade social e econômica a que muitas organizações, sobretudo populares, estão submetidas, conforme alertado pelo próprio FBES. Nesse sentido, inclusive, é a crítica formulada pelo Movimento Nacional dos Catadores de Materiais Recicláveis, que será abordada na sequência.

\section{As críticas do Movimento Nacional de Catadores de Materiais Recicláveis à Lei $\mathbf{n}^{0} \mathbf{1 2 . 6 9 0 / 2 0 1 2}$}

Os catadores de materiais recicláveis cumprem, por meio de seu trabalho, um importante papel nas cidades, sobretudo do ponto de vista ambiental. Todavia, é notória a precariedade de suas condições de trabalho, marcadas pela informalidade, pela estrutura inadequada, por jornadas extenuantes, por instabilidade econômica, pela falta de equipamentos de proteção e pelo descaso com que são, correntemente, tratados pela sociedade e pelo poder público.

Nesse contexto, diversos grupos de catadores têm se articulado procurando formas de, conjuntamente, resolver os problemas enfrentados no seu cotidiano. Em geral, a organização dos catadores potencializa o seu trabalho, pois facilita o acesso a equipamentos, maquinários, e permite a comercialização dos materiais recicláveis em maior escala. Diante da inexistência de um modelo legal específico para a organização dos catadores, as principais formas jurídicas adotadas para tanto são a associação e a cooperativa.

Infelizmente, não há estatísticas precisas sobre o número de catadores de materiais recicláveis existentes no país. Em material elaborado pelo IPEA para subsidiar o processo de elaboração do Plano Nacional de Resíduos Sólidos, concluiu-se que "qualquer definição em torno de um único número total de catadores será necessariamente arbitrária. Um intervalo sugerido, razoavelmente seguro, pois, bastante amplo, vai de 400 a 600 mil indivíduos” (FREITAS; FONSECA, 2011, p. 8).

Além disso, os catadores se organizam politicamente, sobretudo por meio do Movimento Nacional de Catadores de Materiais Recicláveis (MNCR), que surgiu em meado de 1999, durante o $1^{\circ}$ Encontro Nacional de Catadores de Papel, sendo fundado oficialmente em junho de 2001 no $1^{\circ}$ Congresso Nacional dos Catadores(as) de 
Materiais Recicláveis em Brasília, evento que reuniu mais de 1.700 catadores e catadoras.

A existência de um movimento social organizado em torno das pautas desses trabalhadores há mais de 10 anos denota a importância e a força dos catadores, que têm conquistado vitórias nesse percurso. A primeira delas foi o reconhecimento da profissão de catador de material reciclável pelo Ministério do Trabalho e Emprego, que passou a integrar a Classificação Brasileira de Ocupações (CBO) em 2002.

A despeito disso, as condições gerais de exercício dessa profissão, retratadas na $\mathrm{CBO}$, revelam a precariedade e a insegurança a que eles estão submetidos:

O trabalho é exercido por profissionais que se organizam de forma autônoma
ou em cooperativas. Trabalham para venda de materiais a empresas ou
cooperativas de reciclagem. O trabalho é exercido a céu aberto, em horários
variados. O trabalhador é exposto a variações climáticas, a riscos de acidente
na manipulação do material, a acidentes de trânsito e, muitas vezes, à
violência urbana. Nas cooperativas surgem especializações do trabalho que
tendem a aumentar o número de postos, como os de selecionador, triador,
enfardador de sucatas e operador de prensa. (MTE, 2013).

Antes do reconhecimento dessa ocupação, as estatísticas sobre os catadores ficavam dispersas em outras ocupações. Mas agora que estão incluídos na CBO com uma identificação específica, será possível determinar, por exemplo, a quantidade de catadores de materiais recicláveis, o que pode contribuir para a elaboração de políticas públicas voltadas a esse segmento.

Essas condições tão precárias de trabalho, com jornadas extenuantes e grande esforço físico, resultam, de maneira geral, em uma renda mensal baixa, menor que o próprio salário mínimo. A partir da análise de diversos estudos sobre as condições socioeconômicas dos catadores organizados no país, Freitas e Fonseca (2011, p. 13) afirmam que "é razoável supor que a renda média dos catadores não ultrapasse o salário mínimo. Um intervalo sugerido para essa variável vai de $\mathrm{R} \$ 420,00$ a $\mathrm{R} \$ 520,00$. Vale observar que este intervalo diz respeito apenas aos catadores organizados".

Além disso, como regra geral, os catadores, ainda que organizados, não usufruem dos direitos sociais do trabalho, o que significa que quando ficam doentes ou impossibilitados de trabalhar, perdem sua fonte de renda. Nesse mesmo sentido, eles também não têm acesso à previdência social, o que implica a necessidade de continuarem trabalhando mesmo quando idosos, para conseguir manter uma renda mínima.

Essas situações de precariedade do trabalho são enfrentadas cotidianamente pelos catadores de materiais recicláveis. Contudo, isso não significa que não existam Em Debat: Rev. Dig., ISSNe 1980-3532, Florianópolis, n. 10, p. 88-104, jul-dez, 2013. 
tentativas de superá-las. Mas é evidente que um catador, de forma isolada, autônoma, encontra sérias dificuldades para tanto, já que são diversas causas, relacionadas à própria estrutura da indústria da reciclagem e da atual crise do mundo do trabalho.

Delineado o cenário no qual estão inseridos os catadores, pode-se compreender as críticas apresentadas pelo Movimento Nacional de Catadores de Materiais Recicláveis (MNCR) à Lei Federal n 12.690/2012, que regulamenta as cooperativas de trabalho. Como já exposto, uma das principais formas organizacionais adotadas pelos catadores é a cooperativa, sendo que, pelo conceito apresentado na nova legislação, esses empreendimentos se enquadram como cooperativas de trabalho. Dessa forma, as cooperativas de catadores existentes há época da promulgação da lei e aquelas criadas a partir de sua vigência devem se adequar aos critérios e obrigações nela definidos.

Os catadores são, em geral, pessoas com baixa escolaridade, excluídas do mercado formal de trabalho, cuja renda alcança o salário mínimo apenas nos casos em que já há uma estruturação de sua organização, com apoio externo (ONG's, poder público). Assim, é evidente que as cooperativas de catadores enfrentarão muitas dificuldades para cumprir as novas exigências legais, pois elas importam em um aumento significativo das despesas da cooperativa, que já sofrem com a alta carga tributária e com as dificuldades financeiras decorrentes da oscilação do mercado de materiais recicláveis.

Nesse sentido, inclusive, é o posicionamento do Movimento Nacional de Catadores de Materiais Recicláveis - MNCR, que divulgou uma nota a respeito da Lei $n^{\circ} 12.690 / 2012$, em que manifestam a sua desaprovação à regulamentação legal, por entender que inviabiliza as cooperativas de catadores, além de afrontar o princípio da equidade, ao excluir de sua aplicação as cooperativas ligadas a setores de alta lucratividade. Na nota, destacam os seguintes impactos da regulamentação proposta pela lei:

Acreditamos que na prática a lei 12.690/2012, traz os seguintes impactos:

- Mesmo com a carência de um ano para adequação, coíbe a formação de novas cooperativas de catadores de materiais recicláveis, visto que grande parte dos catadores encontram-se em situação de pobreza extrema e a superação dessa realidade só é possível com a formação da cooperativa, no entanto, a nova lei onera ainda mais a atividade;

- Mesmo com a carência de um ano para adequação, coloca em risco jurídico a totalidade das cooperativas de catadores já existentes, por exigir o cumprimento integral da lei 12.690/2012, sem que seja considerada a realidade das cooperativas de catadores e de seu entorno socioprodutivo e solidário;

- O cumprimento das exigências do capítulo 1 , artigo $7^{\circ}$ incisos de I a VII e de seus parágrafos de $1^{\circ}$ a $6^{\circ}$, não são de competência natural dos empreendimentos cooperativos, e sim dos empreendimentos empresariais

Em Debat: Rev. Dig., ISSNe 1980-3532, Florianópolis, n. 10, p. 88-104, jul-dez, 2013. 
mercantis. Na sua estruturação e funcionamento, as Cooperativas de Catadores primam pelos princípios e valores do cooperativismo e da economia popular solidária;

- É oferecida como alternativa ao não cumprimento da lei o puro e simples encerramento das atividades das cooperativas de catadores. (MNCR, 2012).

Logo, de acordo com o entendimento do MNCR, a regulamentação prevista pela Lei Federal no 12.690/2012 inviabiliza as cooperativas de trabalho de catadores de materiais recicláveis por lhes impor em aumento excessivo de ônus, sem que haja mecanismos que permitam alterar a realidade sobre a qual se constituem essas organizações que é, como já apontado, de extrema precariedade, pobreza e submissão a um mercado oligopsônio (em que há um reduzido número de empresas que consome os materiais recicláveis e impõe as condições e os preços aos catadores e cooperativas).

Além disso, o movimento critica a concepção que subjaz a essa regulamentação, qual seja, a de que os empreendimentos solidários devem se adequar totalmente às exigências do mercado, desvirtuando a especificidade das relações cooperativas:

Reforçamos o nosso entendimento de que os empreendimentos populares solidários e da economia solidária, não podem ser transformados em empreendimentos meramente mercantis, conforme o entendimento prático desta lei. Pois garante aos cooperados direitos obrigatórios da relação empregatícia, tradicionalmente as mesmas do trabalhador subordinado ao capital, submetendo os cooperados a um pretenso dono do capital que deverá pagar as obrigações. $\mathrm{Na}$ tradição cooperativista, os associados não são empregados, mas sim seus donos e, portanto, em condições de decidir democraticamente e de participar economicamente em base à sua produção e não em base ao cumprimento de determinações do capital. (MNCR, 2012).

Em relação a esse ponto, é importante apresentar a reflexão de Ricardo Antunes de que essas iniciativas ligadas à economia solidária, em si, não representam uma alternativa efetiva à exploração capitalista do trabalho. Em verdade, elas cumprem "um papel de funcionalidade ao incorporar parcelas de trabalhadores desempregados pelo capital" (ANTUNES, 2003, p. 113). Funcionalidade, por ser um mecanismo de incorporação daqueles que foram expulsos do mercado de trabalho e das relações de emprego assalariado, desonerando o poder público de se preocupar socialmente com uma grande parcela de desempregados. Nesse sentido, não se pode deixar de considerar os limites das iniciativas do "Terceiro Setor" que configuram a economia solidária:

Se dentro do "Terceiro Setor" as atividades que vêm caracterizando a economia solidária têm a positividade de frequentemente atuar à margem da lógica mercantil, parece-me entretanto um equívoco grande concebê-la como uma real alternativa transformadora da lógica do capital e de seu mercado, como capaz de minar os mecanismos da unidade produtiva capitalista. Como se, por meio da expansão da economia solidária, inicialmente pela franja do

Em Debat: Rev. Dig., ISSNe 1980-3532, Florianópolis, n. 10, p. 88-104, jul-dez, 2013. 
sistema, se pudesse reverter e alterar substancialmente a essência da lógica do sistema produtor de mercadorias e da valorização do capital. (ANTUNES, 2003, p. 113).

De fato, há aqueles que defendem que essas iniciativas representam uma alternativa ao sistema do capital. Contudo, ao menos no que se refere às organizações dos catadores, objeto desse estudo, fica evidente o equívoco desse entendimento. A relação umbilical existente entre os catadores e as indústrias de reciclagem, a existência de um mercado oligopsônio, a crise do trabalho e a reestruturação produtiva são fatores mais que suficientes para afirmar, no sentido do que expõe Antunes, que essas experiências não são uma alternativa duradora e efetiva ao mercado de trabalho.

Todavia, isso tampouco retira a importância da organização dos catadores, de sua mobilização, sua luta contra a precariedade do trabalho e da construção da identidade desses trabalhadores enquanto parte da classe-que-vive-do-trabalho (ANTUNES, 2003, p. 101).

\section{Considerações finais}

No final do século XX, as cooperativas tomam novo fôlego no Brasil, como consequência do processo de reestruturação produtiva. Assim, percebe-se um aumento tanto as cooperativas ligadas ao desenvolvimento da economia solidária, quando daquelas criadas por empresas para burlar a legislação trabalhista - as cooperfraudes.

Como resposta ao impasse e à contradição subjacentes a essas transformações, em 2012 foi aprovada a Lei $n^{\circ}$ 12.690, que regulamenta as cooperativas de trabalho. Com o intuito de coibir as cooperativas fraudulentas, uma série de direitos sociais passa a ser assegurado aos trabalhadores cooperados. Contudo, a responsabilidade pela efetivação desses direitos é imputada justamente aos próprios cooperados e à cooperativa, permanecendo praticamente desonerados os contratantes das cooperativas.

Uma primeira aproximação de análise da referida lei nos leva a questionar a sua eficácia para controlar as cooperfraudes. Não bastasse isso, percebe-se que há um grande aumento das obrigações das cooperativas, o que não condiz com a realidade socioeconômica da maior parte dos empreendimentos solidários autênticos.

Nesse sentido, é relevante a posição defendida pelo Movimento Nacional dos Catadores de Materiais Recicláveis, que critica a referida regulamentação por prever impactos negativos às organizações de catadores. Dessa forma, pode-se apontar que, mais do que uma regulamentação, é necessário maior incentivo para que as cooperativas Em Debat: Rev. Dig., ISSNe 1980-3532, Florianópolis, n. 10, p. 88-104, jul-dez, 2013. 
tornem-se economicamente viáveis, além de uma fiscalização no sentido de responsabilizar aqueles que se beneficiam das fraudes.

\section{Referências}

ANTUNES, Ricardo. Adeus ao trabalho? Ensaio sobre as metamorfoses e a centralidade do mundo do trabalho. 14. ed. São Paulo: Cortez, 2010.

Os sentidos do trabalho: ensaio sobre a afirmação e a negação do trabalho. São Paulo: Boitempo, 2003.

BARBOSA, Rosangela Nair de Carvalho. A economia solidária como política pública: uma tendência de geração de renda e ressignificação do trabalho no Brasil. São Paulo: Cortez, 2007.

FREITAS, Lúcio Flávio da Silva; FONSECA, Igor Ferraz da. Caderno de Diagnóstico Catadores. Brasília: IPEA, Ministério do Meio Ambiente. 2011. Disponível em: $<$ http://www.cnrh.gov.br/pnrs/documentos/cadernos/04_CADDIAG_Catadores.pdf $>$ Acesso em: 25 ago. 2013.

HIRATA, Helena. A precarização e a divisão internacional e sexual do trabalho. Sociologias. Porto Alegre, ano 11, n. 21, p. 24-41, jan./jun. 2009.

MNCR. Nota sobre a nova lei de cooperativas de trabalho. 2012. Disponível em: $<$ http://www.mncr.org.br/box_1/notas-e-declaracoes/nota-sobre-a-nova-lei-decooperativas-de-trabalho>. Acesso em: 22 mar. 2014.

MTE. Classificação Brasileira de Ocupações. Disponível em: $<$ http://www.mtecbo.gov.br/cbosite/pages/pesquisas/BuscaPorTituloResultado.jsf $>$. Acesso em: 10 set. 2013.

Portaria $n^{\circ} 925$ de 28/09/1995. Disponível em:

$<$ http://www.mtb.gov.br/legislacao/portaria-n-925-de-28-09-1995.htm>. Acesso em: 20 mar. 2014.

PEREIRA, Luciano Ricardo de Magalhães. O marco jurídico da economia solidária no Brasil: entre a geração de trabalho e renda e a desoneração do capital. Dissertação em Ciência Política, Universidade Federal de Minas Gerais. Belo Horizonte, 2008. 
SENAES/MTE. Avanços e desafios para as políticas públicas de economia solidária no governo federal 2003/2010. Brasília: SENAES, 2012.

SILVA, Selma Cristina. A terceirização via cooperativas de trabalho: precarização ou autonomia? In: DRUCK, Graça; FRANCO, Tânia. A perda da razão social do trabalho: terceirização e precarização. São Paulo: Boitempo, 2007.

SINGER, Paul. Cooperativas de trabalho. 2004. Disponível em:

$<$ http://portal.mte.gov.br/data/files/FF8080812BCB2790012BCF0F046C68D9/prog_co operativatrabalho2.pdf $>$. Acesso em: 15 mar. 2014. 